\title{
Kolmogorov's differential equations and positive semigroups on first moment sequence spaces
}

\section{Maia Martcheva - Horst R. Thieme • \\ Thanate Dhirasakdanon}

Published online: 8 January 2008

(C) Springer-Verlag 2008

Erratum to: J. Math. Biol. (2006) 53:642-671 DOI 10.1007/s00285-006-0002-5

In Sect. 7, for a bounded set $Y$ of a metric space $(X, d)$,

$$
\begin{aligned}
& \alpha(Y)=\inf \left\{c>0 ; \text { each sequence }\left(x_{n}\right) \text { in } Y\right. \text { has a } \\
& \text { subsequence } \left.\left(x_{n_{j}}\right) \text { with } \limsup _{j, k \rightarrow \infty} d\left(x_{n_{j}}, x_{n_{k}}\right) \leq c\right\},
\end{aligned}
$$

is not the sequential characterization of the Kuratowski measure of non-compactness, but of the separation measure of non-compactness [1, II.3].

The separation measure of non-compactness is related to the Kuratowski and the Hausdorff measures of non-compactness, $\alpha_{K}$ and $\alpha_{H}$, by

$$
\alpha_{H}(Y) \leq \alpha(Y) \leq \alpha_{K}(Y) \leq 2 \alpha_{H}(Y), \quad Y \subseteq X .
$$

The results of the paper are not affected.

The online version of the original article can be found under doi:10.1007/s00285-006-0002-5.

\footnotetext{
M. Martcheva $(\varangle)$

Department of Mathematics, University of Florida, 358 Little Hall,

P. O. Box 118105, Gainesville, FL 32611-8105, USA

e-mail: maia@math.ufl.edu

H. R. Thieme · T. Dhirasakdanon

Department of Mathematics and Statistics, Arizona State University,

Tempe, AZ 85287-1804, USA

e-mail: thieme@math.asu.edu

T. Dhirasakdanon

e-mail: thanate@asu.edu
} 


\section{Reference}

1. Ayerbe Toledano, J.M., Dominguez Benavides, T., López Acedo, G.: Measures of Noncompactness in Metric Fixed Point Theory. Birkhäuser, Basel (1997) 